\title{
A Philosophical Defense of Ecological Sensitivity in the Business World
}

\begin{abstract}
Sachdev $\mathrm{KN}^{*}$
Department of Humanities and Social Sciences, Birla Institute of Technology and Science, India
\end{abstract}

*Corresponding author: Kumar Neeraj Sachdev, Associate Professor of Philosophy, Department of Humanities and Social Sciences, Birla Institute of Technology and Science (BITS), Pilani Campus, Pilani-333031, Rajasthan, India, Email: kns@pilani.bits-pilani.ac.in

\section{Mini Review \\ Volume 4 Issue 2}

Received Date: March 22, 2021

Published Date: April 09, 2021

DOI: $10.23880 /$ abca-16000176

\section{Abstract}

An attempt is made in the paper to analyze the nature of virtue of ecological sensitivity to argue for its relevance and need in the business world. Ecological sensitivity is a virtue or quality of a human being to relate himself to the environment in a protective spirit of oneness. It is not a virtue by extension from human to environment like compassion or empathy but a virtue of independent normative standing since it is argued to be equal to other personal and inter-personal virtues in the pool of virtues to live a good human life. It is further argued that since ethics is a study of values and virtues to live a good human life and business companies are a great source to sustain and improve upon the state of mankind in the world and the condition of planet earth itself, it makes sense to emphasize the need to include ecological sensitivity as a virtue in the conduct of business professionals. It also attempts to understand how the business professionals ought to interpret ecological sensitivity in and around their surroundings on a daily basis.

\section{Introductory Remarks}

An attempt is made in the paper to analyze the nature of the virtue of ecological sensitivity to argue for its relevance in the conduct of business professionals. In this regard, the analysis begins with an elaboration of the nature of environmental virtue ethics and goes on to philosophically defend the need for the virtue of ecological sensitivity in the conduct of business professionals.

\section{Towards Environmental Virtue Ethics}

The idea of applying ethics helps because one learns to appreciate the relevance of values and principles in the ethical analysis of a situation. For example, it is good to learn about the nature of biological and non-biological entities but it is equally good to learn to appreciate a person's moral responsibility to protect and conserve these entities. Or else, it is good to comprehend efficient allocation of resources in business decision making but it is equally good to know one's obligation to acknowledge environmental responsibility, or rights of stakeholders such as employee rights or rights of local community. In a similar vein, an awareness of ethical issues as they are put forward in the study of environmental ethics, which is an example of applied ethics - such as air and water pollution; preservation of wild life and wild lands; population increase (locally, nationally and internationally); global climate change; transportation systems; agricultural practices [1], etc. may help to determine the nature of ought for human beings to protect the environment.

We may note in this regard, "Environmental ethics is a branch of applied philosophy that studies the conceptual foundations of environmental values as well as more concrete issues surrounding societal attitudes, actions, and policies to protect and sustain biodiversity and ecological systems" [2].

It basically deals with human-environment interactions and relationships. So I can say that environmental ethics not only focuses on ethics of action but it also teaches what one 
must and must not do to the environment. It argues that an ethics of character provides guidance as to what attitudes and dispositions one ought to have. Environmental virtues are the character traits of human beings which one needs to cultivate to understand the interactions and relationships with the environment. Thus, I maintain that environmental virtue ethics focuses on the questions "How should one live a good human life in tune with the life processes of nature as a whole?" A person who is environmentally virtuous is rationally disposed to respond both emotionally and through action to the environment in which he lives and also to the non-human life system.

In fact, I argue that environmental virtue ethics goes beyond the point of views of human-centered ethics, animalcentered ethics, and life-centered ethics that includes humans, animals or even plants (or the whole biosphere) as morally considerable. It includes apart from these morally considerable entities in its point of views ecological holism. The view counts as morally considerable the biosphere as a whole and the large ecological system that refers to a community of living organisms in conjunction with the nonliving components of their environment, interacting as a system, which constitute it morally considerable [3]. Every particle of nature in other words matters in the life and conduct of environmentally virtuous person and he identifies himself with the system.

Any particular character trait as constitutive of environmental virtue does benefit its possessor because health of environment as such benefits moral agents. As we know that nature provides not only material goods such as clean water and air but it also provides us aesthetic goods, recreational goods, and a healthy surrounding where we can develop physically, intellectually, morally, and aesthetically. Thus, it serves as a reason for human beings as moral agents to preserve these gifts of nature.

Environmental virtue ethics also encompasses a motivation of turning a human being into a good human being. We humans are social beings and we have the ability to promote the good functioning of social groups and encourage one to maintain healthy relationships with members in the group. Adding to this, many philosophers argue that in order to have a naturalistic understanding of human beings one needs to understand humans as members of society and also as members of biotic community. Therefore, I may contend that goodness of a human being would be achieved when one also aims to promote and maintain well-being of the larger ecological community. The attitude of respecting species and ecosystems for their own sakes is a result of willingly accepting an ecological worldview [2].

Alongside it may be observed that environmental virtue ethics aims to challenge the separation of science and ethics, because science finds nature value-free and human centered ethics assumes that only humans count morally. The general thrust of applied science is to protect only human species at the cost of other life systems whereas environmental virtue ethics seeks to discover a way past human-centered ethics. Environmental virtue ethics is the only ethics that breaks out of human-centered approach because it evaluates nature, both the nature that mixes with human culture and wild nature [4].

\section{Ecological Sensitivity as a Virtue}

TheAristotelian conception of virtue standsfor excellence, disposition, inclination or habit that is characteristic of a rational control in human activity to live a good life. "Aristotle famously defined excellence in a particular area of human activity as the mean between deficiency and excess in that area" [5] Ecological sensitivity as a virtue refers to a human disposition in its own independent normative sense and not a mere extension of personal or inter-personal virtues such as compassion or empathy. It is a disposition towards natural environment that enables a human being to act in a protective spirit of oneness no matter if the disposition is directed towards a small gesture of walking to the office instead of using the car. The virtuous person considers himself as a part of nature and sensitive to the need for conservation of nature. He doesn't wish to dominate nature for his own sake but works for the conservation of nature for its own sake, for its own intrinsic value.

We may note that the typical interaction between a human being and the natural environment is not something that takes place outside towns and cities away from human habitats but in day-to-day decisions that we make and human activities that we perform, for instance, the food we eat, the cars we drive or choose not to drive, the candidates we vote for or do not vote for, the way we dispose of waste especially e-waste, the light bulbs we install, the way we invest money, the clothes we wear, the recreation we take' [5]. Precisely, we are always living in natural environment (air, water and land) and we regularly interact with and impress upon it.

There is a dire need of cultivation of ecological sensitivity among humans to preserve the environment and natural resources, so that they can be used in a sensible way, rather than being wasted. Ecological sensitivity is defined by Hungerford et.al as "a view of the environment, which is characterized by the individual who 'refuses to litter highways and natural areas, conserves natural resources, works to preserve ecologically important natural areas, strives for a stable and appropriate human population level, respects hunting and fishing laws and insists on rational zoning requirements etc" [6]. 
The need to be ecologically sensitive is the need for survival of not only humans but the whole planet earth itself. As we are dependent and interconnected with the environment around us, any imbalance in one causes a disturbance in the whole system, which could gradually lower our chances of survival. And this in turn will affect our future generations. Being aware of our surroundings increases our sensitivity and with the right knowledge and attitude, one can contribute to natural resources conservation. One can acquire this knowledge by direct interaction with the environment or by knowing and analyzing the experiences of others. Today our fast moving lifestyles, computer mediated work culture, de-forestation, use of inorganic farming methods unhealthy food habits, water and air pollution, crowding of cities, lack of drinking water and lifestyle as a whole are some perceived dangers to the environment that have a detrimental effect on us. These are all manmade dangers to which we humans need to pay serious attention to as they are resulting in increased number of diseases, depletion of water resources, reducing green coverage, shortage of food etc.

And as "social creatures" we must have a sense of responsibility that we are answerable to our present and future generations and more importantly, each of us ought to have a sense of responsibility towards the whole ecosystem for the sake of nature [7]. A virtuous person exhibits environmental sensitivity in his disposition to relate himself to the natural environment in a protective spirit of oneness. "Ecological sensitivity is the virtue applicable to human activities and interactions with the natural environment... So, for example, an individual considering whether to clearcut a stand of old-growth forest to improve his view from his window must consider whether his action is ecologically sensitive" [5].

Like character development is the aim of virtue ethics, environmental virtue ethics aims to develop those dispositions in humans that protect the whole ecological system in a spirit of oneness. This is in one way possible by developing the virtue of 'environmental sensitivity'. When one becomes sensitive towards the need of his natural surroundings, when one becomes conscious about conserving the environment, when one understands that our clean environment and healthy lifestyle is the basis for human flourishing only then one really adapts to the virtue of environmental sensitivity. And when the cooperation is exemplified through virtuous actions it gives all human species a place to flourish and develop [8].

\section{Making Sense of Ecological Sensitivity in the Conduct of Business Professionals}

The need to make sense of ecological sensitivity as a virtue in the conduct of business professionals is well- connected to the fact that a business professional is assumed to possess intellectual ability through extensive training to give advice or service rather than material things in his field of expertise in a spirit of service to the mankind in the world. Correspondingly, the understanding and reflection of good human life makes sense in every sphere of life but it calls for a special sense of duty and a set of obligations that assume a level of overriding character in the conduct of business professionals $[9,10]$.

It further implies that we humans happen to play many given or adopted roles but the role of a business professional has to have an edge over other roles be that of a brother or an employee. The role of a business professional entails a set of obligations to a society, the world, the whole mankind or the planet earth itself [11]. In accord with this set of obligations business professionals ought to cultivate ecological sensitivity as a virtue to protect the whole ecological system and it is understandable that since he has the expertise and the duty to provide quality products and services to customers in a society, he ought to cultivate this virtue in his life to protect the whole ecological system [12].

He ought to be disposed to act like an exemplar in his area of expertise. For instance, an automobile engineer is not expected to drive in a pollution emitting vehicle and still on a higher plane I may contend that he is not supposed to design or sell a vehicle of a business company that is detrimental to the environment. He ought to think of the invention and use of those technologies and materials in the design of a vehicle that may not harm the natural environment [12].

Similarly, a scientist working in a business company is not supposed to use pesticides that are harmful to the environment. Instead, he ought to be disposed to be sensitive to the conservation of natural environment and thus may do research on making pesticides that are harmless to the underground water and the living and non-living beings on the ground.

On the whole, I may contend that since business professionals are experts in their area of specialization, they are well expected to possess ecological sensitivity [13]. That is to say, they ought not to harm the natural environment by way of their personal or professional conduct in the living of their lives or running of their business companies. Instead they ought to devise ways and means in their professional practices to conserve the natural environment.

\section{Concluding Remarks}

Ecological sensitivity is an important virtue in environmental virtue ethics especially in the context of the need to conserve the natural environment for the sake of 
whole planet earth. And the natural urge to live a good human life leads a business professional to acknowledge the need to cultivate ecological sensitivity as a virtue in his conduct and since, the practice of a profession in a business company implies the acquisition and application of knowledge in a formal setup for selling of quality products and services, the cultivation of ecological sensitivity as a virtue enables a business professional to think in a morally responsible manner and act in a protective spirit of oneness with the whole ecological system for the sake of whole mankind and the planet earth itself.

\section{References}

1. Cafaro P (2003) Environmental Ethics and the Business Professional: Responsibilities and Opportunities, Ethics for the Professions, Wadsworth, pp: 189-197.

2. Minteer BA (2013) Environmental Ethics. The nature education knowledge project.

3. Elliot R (1993) Environmental Ethics, A Companion to Ethics, Blackwell, pp: 284-293.

4. Rolston H (2009) Environmental Ethics: Values in and Duties to the Natural World.
5. Sandler R (2004) Towards an Adequate Environmental Virtue Ethic, Environmental Values 13(4): 477-495

6. Sivek DJ (2002) Environmental Sensitivity among Wisconsin High School Students. Environmental Education Research 8(2): 155-170.

7. Subha (2009) Sensitivity towards nature.

8. Sandler R, Cafaro P (2005) Environmental Virtue Ethics. Oxford: Rowman \& Littlefield.

9. Barnes J (2004) Aristotle Introduction to Further Reading, Penguin Books, Nicomachean Ethics.

10. John RB, Prasan Patra B (2009) Ethics and the Conduct of Business, Pearson Education, $6^{\text {th }}$ (Edn.), Indian Reprint.

11. King-Tak IP (2009) Environmental Ethics: Intercultural Perspectives.

12. Athanassoulis N, (2010) Virtue Ethics. Internet Encyclopedia of Philosophy.

13. Sandler R (2012) Global Warming and Virtues of Ecological Restoration. In: Thompson A, et al. (Eds.), Ethical Adaptation to Climate Change: Human Virtues of the Future. The MIT Press. 